\title{
Circadian rhythm of COPD symptoms in clinically based phenotypes. Results from the STORICO Italian observational study
}

Nicola Scichilone ${ }^{1 *}$ (D), Raffaele Antonelli Incalzi ${ }^{2}$, Francesco Blasi ${ }^{3}$, Pietro Schino ${ }^{4}$, Giuseppina Cuttitta ${ }^{5}$ Alessandro Zullo ${ }^{6}$, Alessandra Ori ${ }^{6}$, Giorgio Walter Canonica ${ }^{7}$ and on behalf of STORICO study group

\begin{abstract}
Background: Chronic Obstructive Pulmonary Disease (COPD) encompasses various phenotypes that severely limit the applicability of precision respiratory medicine. The present investigation is aimed to assess the circadian rhythm of symptoms in pre-defined clinical COPD phenotypes and its association with health-related quality of life (HRQoL), the quality of sleep and the level of depression/anxiety in each clinical phenotype.

Methods: The STORICO (NCT03105999) Italian observational prospective cohort study enrolled COPD subjects. A clinical diagnosis of either chronic bronchitis (CB), emphysema (EM) or mixed COPD-asthma (MCA) phenotype was made by clinicians at enrollment. Baseline early-morning, day-time and nocturnal symptoms (gathered via the Night-time, Morning and Day-time Symptoms of COPD questionnaire), HR-QoL (via the St. George's Respiratory Questionnaire), anxiety and depression levels (via the Hospital Anxiety and Depression Scale), quality of sleep (via COPD and Asthma Sleep Impact Scale), physical activity (via the International Physical Activity Questionnaire) as well as lung function were recorded.

Results: 606 COPD subjects (age $71.4 \pm 8.2$ years, male 75.1\%) were studied. 57.9, 35.55 .3 and 1.3\% of the sample belonged to the $C B, E M, M C A$ and EM + CB phenotypes respectively. The vast majority of subjects reported earlymorning and day-time symptoms (79.5 and $79.2 \%$ in the CB and 75.8 and $77.7 \%$ in the EM groups); the proportion suffering from night-time symptoms was higher in the CB than in the EM group ( $53.6 \%$ vs. $39.5 \%, p=0.0016)$. In both $C B$ and $E M$, indiscriminately, the presence of symptoms during the 24-h day was associated with poorer HRQoL, worse quality of sleep and higher levels of anxiety/depression.
\end{abstract}

Conclusions: The findings highlight the primary classificatory role of nocturnal symptoms in COPD.

Trial registration: Trial registration number: NCT03105999, date of registration: 10th April 2017.

Keywords: 24-hour symptoms, Clinical phenotype, Respiratory function, Real-world

\section{Background}

Chronic Obstructive Pulmonary Disease (COPD) is a common, preventable condition characterized by persistent airflow limitation, initiated and sustained by chronic exposure to smoke and other irritants [1]. The complexity and the heterogeneous clinical presentation of the disease, however, requires a more comprehensive approach, obliging physicians to take account of symptoms and exacerbations, and to manage the concomitant occurrence of extra-pulmonary

\footnotetext{
* Correspondence: nicola.scichilone@unipa.it; medidata@medineos.com 'DIBIMIS, University of Palermo, Piazza delle Cliniche, 2, 90127 Palermo, Italy Full list of author information is available at the end of the article
}

pathological conditions. It is evident, on this basis, that Burrows and Fletcher's original proposal of emphysematous and bronchitic phenotypes [2] is no longer sufficient to identify the different clinical forms of the disease in clinical practice. A COPD phenotype is considered to be a set of attributes that can help differentiate patients on the basis of clinically meaningful parameters, such as symptoms, exacerbations, progression of disease decline, physical inactivity, response to treatment, and mortality.

One effort to classify COPD individuals according to their clinical presentations is the Spanish COPD guidelines [3], which distinguish the emphysema from the

(c) The Author(s). 2019 Open Access This article is distributed under the terms of the Creative Commons Attribution 4.0 International License (http://creativecommons.org/licenses/by/4.0/), which permits unrestricted use, distribution, and 
chronic bronchitic phenotype and also consider the rate of exacerbations. In addition, a mixed COPD-asthma phenotype (asthma-COPD overlap [ACO]) has been proposed, although its interpretation and association with exacerbation and mortality are now controversial [4-6]. Distinguishing the bronchitic from the emphysematous phenotype is apparently an easy task. The former is marked by productive cough and early onset of hypoxemia, with high prevalence of respiratory failure and chronic cor pulmonale, whereas the latter displays early and severe dyspnea with late-onset hypoxemia. Hypothetically, these clinical presentations could benefit selectively by the treatment options available, but, in real life settings the spectrum of therapies is variably distributed across the range of severity of COPD, without any distinction in terms of phenotypes, thus making such personalized care treatment more difficult.

Taken together, these observations show the need for deeper understanding of the clinical phenotypes of COPD. The STORICO study (STudio Osservazionale sulla caratteRizzazione dei sIntomi delle 24 ore nei pazienti con broncopneumopatia cronica ostruttiva, Observational study on characterization of 24-h symptoms in patients with $C O P D$ ) offers a unique opportunity to analyze the clinical characteristics of subjects with COPD in relation to the 24-h day-long variability of symptoms. For example, given that dyspnea depends mainly on physical effort, it is logical to expect this symptom to be far more evident during daytime, and in EM subjects.

To reinforce the classical phenotyping strategy, this paper aims primarily to assess, within the clinical COPD phenotypes, the circadian rhythm of COPD symptoms at baseline (in terms of frequency of early-morning, day-time and night-time symptoms). As secondary objective, for each clinical phenotype, we investigated the potential association at enrollment of the circadian variability of symptoms with both disease severity and selected indicators of health status.

\section{Method}

\section{Study design}

STORICO (NCT03105999) is an Italian, multicenter observational prospective cohort study conducted in 40 pulmonology referral care centers. The enrollment started in February 2016 and the 1-year longitudinal phase of the study ended in June 2018; a total of three visits (baseline and follow-up at 6-month intervals) were performed. The present paper reports the results of the cross-sectional phase. More details about the STORICO study are available elsewhere [7].

\section{Subjects}

Subjects of both sexes aged $\geq 50$, current or former smokers with a smoking history of at least 10 pack-years, with a diagnosis of COPD and in stable conditions for at least 12 months according to GOLD 2014 [8] were enrolled consecutively. Patients provided written, informed consent before participation. Patients participating in a clinical trial and those who had changed their COPD treatment regimen in the 3 months prior to enrolment were excluded, as were patients with recent exacerbations (within 1 month prior to enrollment). Also, patients under continuous use of oxygen therapy or suffering from asthma, sleep apnea syndrome or other chronic diseases that reduced life expectancy to less than 3 years (Charlson index $>3$ ) were excluded. Among enrolled patients, only those with available information on the frequency of COPD symptoms during each part of the 24-h day were analyzed.

The sample size was determined by criteria of feasibility. In fact, given the volume of patients handled by the centers involved in the study, inclusion of approximately $600 \mathrm{sub}$ jects with the characteristics defined by the Inclusion/Exclusion criteria was deemed reasonable. An evaluation of the possible precision of the estimates was performed in consideration of the primary objectives, finding that a sample of 100 patients per group (i.e. per class of phenotype) would allow precise estimates of the expected proportion of COPD symptoms $\geq 30 \%$. More details concerning sample size justification are provided elsewhere [7].

\section{Clinical assessment}

On the first assessment day, anthropometric data and clinical history were collected and each subject was assigned a clinical COPD phenotype based on the judgment of the clinician: chronic bronchitis (CB), defined as the presence of productive cough for at least 3 months in two consecutive years; emphysema (EM), for patients whose predominant symptoms are dyspnea and reduced tolerance to exercise; mixed COPD-asthma (MCA) for patients with documented not completely reversible airflow obstruction, accompanied by symptoms or signs of obstruction reversibility $[9,10]$. As part of the investigation, local researchers were asked to express their degree of confidence in the choice of clinical phenotype on a scale of 0 to 10 , from no confidence at all to maximum of confidence. Disease severity was defined using the combined COPD assessment according to GOLD [11]. Spirometry was performed according to the recommendations of the American Thoracic Society (ATS) and the European Respiratory Society (ERS); forced expiratory volume in the first second $\left(\mathrm{FEV}_{1}\right)$ and forced vital capacity (FVC) were retained for analysis. Although not mandatory by protocol, the centers were invited to record static lung volumes, and Residual Volume (RV) and Total Lung Capacity (TLC) were obtained together with diffusion capacity for carbon monoxide (DLCO), in order to support the clinical assignment of subjects to the phenotypes. 


\section{Multidimensional assessment}

According to the study design, subjects completed the Night-time, Morning and Day-time Symptoms of COPD questionnaire [12]). This is a 33-item questionnaire developed by Almirall S.A., Barcelona, Spain covering the frequency and severity of COPD symptoms (breathlessness, coughing, bringing up phlegm or mucus, chest tightness, chest congestion and wheezing) during each part of the day. This represented the primary outcome of the study.

The questionnaire includes 13 symptom items for night-time (i.e. the time between going to bed and getting up), 10 symptom items for early-morning (i.e. the time from getting up until approximately 11:00 am) and 10 symptom items for day-time (i.e. from approximately 11 : 00 am until the subject goes to bed).

To address the secondary outcomes of the study the following measures were performed: the level of perceived breathlessness and the extent to which it affected mobility were assessed by the modified Medical Research Council (mMRC) dyspnea scale ranging from 0 (breathless with strenuous exercise) to 4 (too breathless to leave the house or breathless when dressing or undressing) [13]; healthrelated quality of life (HR-QoL) was evaluated by the $S t$. George's Respiratory Questionnaire (SGRQ), including the subject's perception of recent respiratory problems (Symptoms component), disturbances to daily physical activity (Activity component) and disturbances of psycho-social function (Impact component); a total score was also calculated. Scores range from 0 (no impairment) to 100 (highest impairment) [14-17], anxiety and depression states were investigated through the Hospital Anxiety and Depression
Scale (HADS) [18-20], with a total score (emotional distress) ranging from 0 to 42; anxiety and depression subscale scores (range 0-21) were also computed, higher scores indicating more distress; the impact of respiratory symptoms on sleep was assessed by the COPD and Asthma Sleep Impact Scale (CASIS) [21], a self-administered, 7-item scale. The total score range is $0-100$, with higher scores indicating greater sleep impairment in the previous week; physical activity was assessed with the International Physical Activity Questionnaire (IPAQ) [22, 23] and a categorical score (low, medium, high level of physical activity) was calculated.

The presence of relevant comorbidities and the number of exacerbations/year in the 5 years before enrollment were recorded. In particular, the presence of anemia was defined as hemoglobin $<13.5 \mathrm{~g} / \mathrm{dl}$ (for males) and $<12 \mathrm{~g} / \mathrm{dl}$ (for females), and an estimated glomerular filtration rate $($ eGFR $)<60 \mathrm{~mL} / \mathrm{min} / 1.73 \mathrm{~m}^{2}$ was considered as indicator of chronic kidney disease [24]. The eGFR was calculated according to the equation proposed by the Chronic Kidney Disease Epidemiology Collaboration [25].

\section{Statistical analysis}

Descriptive statistics were calculated both overall and within each phenotype: mean and standard deviation (SD), median, interquartile range (IQR) for quantitative variables and absolute and relative frequency for categorical variables.

Missing values were not replaced and did not contribute to the analysis of the variable. Frequencies of missing data were given for all analyzed variables.

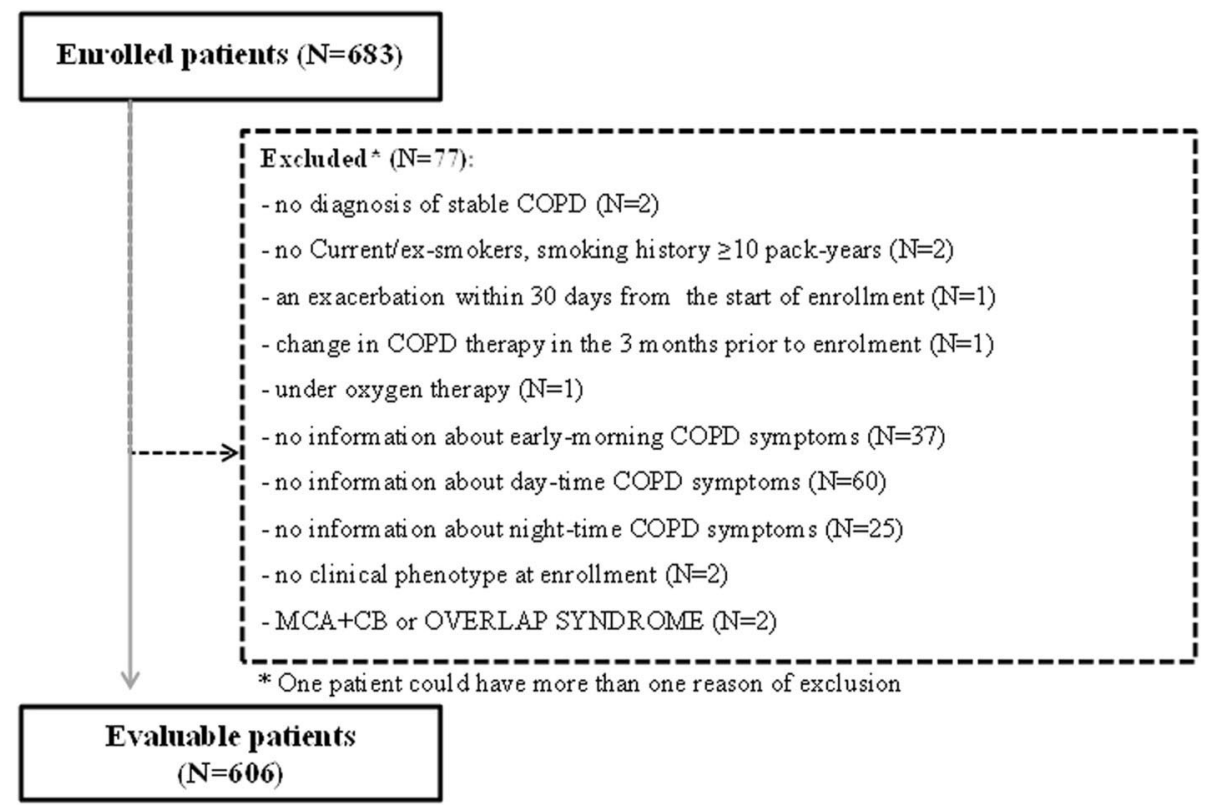

Fig. 1 Patients enrolled and included in the analyses. CB: Chronic Bronchitis; MCA: Mixed-COPD asthma 
Table 1 Socio-demographic, clinical and biological characteristics of the subjects

\begin{tabular}{|c|c|c|c|c|}
\hline & Overall $(N=606)$ & $C B(N=351)$ & $\mathrm{EM}(N=215)$ & $\operatorname{MCA}(N=32)$ \\
\hline Age (yrs) (mean \pm SD) & $71.4 \pm 8.2$ & $71.6 \pm 8.3$ & $71.5 \pm 7.9$ & $70.1 \pm 8.2$ \\
\hline Males (N, \%) & $455(75.1)$ & $256(72.9)$ & $174(80.9)$ & $20(62.5)$ \\
\hline \multicolumn{5}{|l|}{ Education (N, \%) } \\
\hline None & $4(0.7)$ & $3(0.9)$ & 0 & 0 \\
\hline Primary school & $173(29.6)$ & $111(32.8)$ & $54(25.7)$ & $7(22.6)$ \\
\hline Middle school & $241(41.2)$ & $127(37.6)$ & $93(44.3)$ & $19(61.3)$ \\
\hline High school & $133(22.7)$ & $76(22.5)$ & $51(24.3)$ & $4(12.9)$ \\
\hline University & $34(5.8)$ & $21(6.2)$ & $12(5.7)$ & $1(3.2)$ \\
\hline NK & 21 & 13 & 5 & 1 \\
\hline \multicolumn{5}{|l|}{ Occupational status (N, \%) } \\
\hline Unemployed & $23(3.8)$ & $16(4.6)$ & $5(2.4)$ & $2(6.5)$ \\
\hline Employed & 77 (12.8) & $44(12.6)$ & $25(11.7)$ & $5(16.1)$ \\
\hline Retired & $468(77.9)$ & $265(75.9)$ & $176(82.6)$ & $22(71.0)$ \\
\hline Housewife/househusband & $33(5.5)$ & $24(6.9)$ & $7(3.3)$ & $2(6.5)$ \\
\hline NK & 5 & 2 & 2 & 1 \\
\hline \multicolumn{5}{|l|}{ Smoking status (N, \%) } \\
\hline Former smoker & $445(73.4)$ & $250(71.2)$ & $166(77.2)$ & $25(78.1)$ \\
\hline Current smoker & $161(26.6)$ & $101(28.8)$ & $49(22.8)$ & $7(21.9)$ \\
\hline Estimated amount of tobacco consumed (pack/year) (median IQR) & $39.0(20.0-50.0)$ & $35.0(20.0-52.0)$ & $40.0(23.0-50.0)$ & $30.0(20.0-45.0)$ \\
\hline Smoking duration (yrs) (median IQR) & $40.0(30.0-49.5)$ & $40.0(30.0-50.0)$ & $40.0(32.0-50.0)$ & $39.0(30.0-42.0)$ \\
\hline \multicolumn{5}{|l|}{ BMI $(N, \%)$} \\
\hline Underweight (BMl < 18.5) & $13(2.2)$ & $4(1.2)$ & $9(4.2)$ & 0 \\
\hline Normal weight (BMI 18.5-24.9) & $183(30.5)$ & $90(26.0)$ & $81(37.9)$ & $11(34.4)$ \\
\hline Overweight (BMI 25-29.9) & $272(45.3)$ & $163(47.1)$ & $91(42.5)$ & $16(50.0)$ \\
\hline Obese (BMI $\geq 30)$ & $132(22.0)$ & $89(25.7)$ & $33(15.4)$ & $5(15.6)$ \\
\hline NK & 6 & 5 & 1 & 0 \\
\hline \multicolumn{5}{|l|}{ Comorbidities (N, \%) } \\
\hline$\geq 1$ comorbidity & $446(73.6)$ & $254(72.4)$ & $163(75.8)$ & $23(71.9)$ \\
\hline Anemia $^{a}$ & $36(26.7)$ & $26(33.8)$ & $8(16.0)$ & $2(33.3)$ \\
\hline Arterial Hypertension & $308(50.8)$ & $188(53.6)$ & $97(45.1)$ & $17(53.1)$ \\
\hline Atrial fibrillation & $34(5.6)$ & $20(5.7)$ & $12(5.6)$ & $2(6.3)$ \\
\hline Cardiac ischemic disease & $63(10.4)$ & $35(10.0)$ & $21(9.8)$ & $6(18.8)$ \\
\hline Diabetes & $65(10.7)$ & $40(11.4)$ & $20(9.3)$ & $4(12.5)$ \\
\hline GERD & $24(4.0)$ & $14(4.0)$ & $8(3.7)$ & $2(6.3)$ \\
\hline Neoplastic disease & $31(5.1)$ & $10(2.8)$ & $17(7.9)$ & $3(9.4)$ \\
\hline Osteoporosis & $26(4.3)$ & $19(5.4)$ & $5(2.3)$ & $1(3.1)$ \\
\hline \multicolumn{5}{|l|}{ Blood tests } \\
\hline \multirow[t]{2}{*}{$\mathrm{eGFR}<60 \mathrm{~mL} / \mathrm{min} / 1.73 \mathrm{~m}^{2}(\mathrm{~N}, \%)$} & $n=122$ & $n=65$ & $n=49$ & $n=6$ \\
\hline & $17(13.9)$ & $11(16.9)$ & $4(8.2)$ & $2(33.3)$ \\
\hline \multirow[t]{2}{*}{ Hemoglobin $(\mathrm{g} / \mathrm{dl})($ mean $\pm \mathrm{SD})$} & $n=135$ & $n=77$ & $n=50$ & $n=6$ \\
\hline & $14.0 \pm 1.7$ & $13.8 \pm 1.8$ & $14.4 \pm 1.4$ & $13.2 \pm 1.1$ \\
\hline \multirow[t]{2}{*}{ Mean cell volume $(\mathrm{fl})($ mean $\pm \mathrm{SD})$} & $n=106$ & $n=64$ & $n=35$ & $n=6$ \\
\hline & $90.8 \pm 7.9$ & $90.4 \pm 7.7$ & $91.2 \pm 7.7$ & $93.0 \pm 11.4$ \\
\hline Eosinophil count (n/mm³) (median IQR) & $n=129$ & $n=75$ & $n=47$ & $n=6$ \\
\hline
\end{tabular}


Table 1 Socio-demographic, clinical and biological characteristics of the subjects (Continued)

\begin{tabular}{|c|c|c|c|c|}
\hline & Overall $(N=606)$ & $\mathrm{CB}(N=351)$ & EM $(N=215)$ & MCA $(N=32)$ \\
\hline & $2.3(0.1-166.0)$ & $3.0(0.1-190.0)$ & $4.0(0.1-166.0)$ & $0.1(0.0-0.1)$ \\
\hline \multirow[t]{2}{*}{ Serum creatinine (mg/dL) (median IQR) } & $n=122$ & $n=65$ & $n=49$ & $n=6$ \\
\hline & $0.9(0.7-1.1)$ & $0.9(0.8-1.1)$ & $0.8(0.7-1.0)$ & $0.8(0.7-1.2)$ \\
\hline \multicolumn{5}{|l|}{ Ongoing therapies for COPD $(\mathrm{N}, \%)$} \\
\hline$\geq 1$ & $525(86.6)$ & $311(88.6)$ & $183(85.1)$ & $27(84.4)$ \\
\hline Triple therapy (LABA, LAMA, ICS) & $187(30.9)$ & $116(33.0)$ & $62(28.8)$ & $7(21.9)$ \\
\hline LABA+LAMA & $143(23.6)$ & $58(16.5)$ & $75(34.9)$ & $8(25.0)$ \\
\hline LAMA Alone & $90(14.9)$ & $66(18.8)$ & $23(10.7)$ & $1(3.1)$ \\
\hline$I C S+L A B A$ & $78(12.9)$ & $53(15.1)$ & $17(7.9)$ & $8(25.0)$ \\
\hline LABA Alone & $18(3.0)$ & $12(3.4)$ & $4(1.9)$ & $2(6.3)$ \\
\hline Other & $9(1.5)$ & $6(1.7)$ & $2(0.9)$ & $1(3.1)$ \\
\hline
\end{tabular}

Data about $\mathrm{EM}+\mathrm{CB}$ not shown

$B M I$ body mass index. CB Chronic Bronchitis. eGFR estimated glomerular filtration rate. EM Emphysema. GERD Gastroesophageal Reflux Disease. ICS Inhaled corticosteroids. IQR interquartile range. LABA long-acting beta-agonist. LAMA long-acting muscarinic antagonists. MCA Mixed-COPD asthma. NK Unknown. SD standard deviation; Triple therapy includes any combination of LABA, LAMA, ICS

aPresence of anemia was evaluated for 135 patients in the total sample, 77 CB, $50 \mathrm{EM}, 6 \mathrm{MCA}$

Percentages computed out of non-missing responses

\section{Primary objective}

The frequency of COPD symptoms at enrolment was calculated overall and within each class of phenotype as the ratio between the number of patients with at least 1 (early-morning, day-time and night-time) symptom in the week before enrollment and the total number of evaluable patients in the class. Among the symptomatic patients, the proportion suffering from mild, moderate, severe and very severe symptoms in the week before enrollment was also calculated (overall and by clinical phenotype). The $95 \%$ confidence intervals for the proportions were provided when relevant.

\section{Secondary objective}

The association between the circadian variability of COPD symptoms and disease severity at enrollment was evaluated by calculating the frequency of patients with early-morning, day-time and night-time symptoms in the groups of patients according to disease severity (groups A to D of Global Initiative for Chronic Obstructive lung Disease (GOLD)2014 combined assessment). HR-QoL (SGRQ scores), quality of sleep (CASIS score), anxiety and depression (HADS scores), level of physical activity (IPAQ categorical score) at enrollment in patients with vs without early-morning, day-time and night-time symptoms were described and compared using T-test and Chi-square or Fisher exact test (in the case of non-parametric distribution). The significance threshold was adjusted for multiple comparisons (Bonferroni correction applied) and set to 0.0005 (0.05/number of tests). Site monitoring, data management and statistical analysis were performed by MediNeos an IQVIA Company (Modena, Italy). Statistical analysis was performed using SAS v9.4 and
Enterprise Guide v7.1. More details about the STORICO methodology are available elsewhere [7].

\section{Results}

\section{Subject characteristics}

Among the 683 COPD individuals enrolled in the STORICO study, 606 (88.7\%) subjects (age $71.4 \pm 8.2$ years, $75.1 \%$ males) were deemed eligible for the analysis at enrollment; violations causing exclusion are shown in Fig. 1. A total of 351 subjects $(57.9 \%)$ were classified as $\mathrm{CB}, 215$ (35.5\%) as EM and $32(5.3 \%)$ as MCA. In addition, 8 subjects (1.3\%) were classified as $\mathrm{EM}+\mathrm{CB}$ and not retained for analysis due to the paucity of data. When asked for their level of confidence in attributing the phenotype, the vast majority of physicians $(77.0 \% \mathrm{CB}, 78.4 \% \mathrm{EM}, 58.6 \% \mathrm{MCA})$ rated it at least $\geq 6$ out of 10 . Baseline socio-demographic and clinical characteristics (including ongoing therapies for COPD) for each clinical phenotype are shown in Table 1. Table 2 describes the clinical and functional characteristics of subjects according to phenotype. By comparison with EM phenotype, $\mathrm{CB}$ patients were more commonly overweight and had more exacerbations/year in the 5 years before baseline (median (IQR): 2 [1-4] in CB vs. 1 (0-2) in EM). As shown in Table 3, the SGRQ components and the total score were similar across phenotypes and, similarly, the CASIS score and the HADS scores did not differ between groups. On the other hand, low levels of physical activity were observed for $35.4 \%$ of $\mathrm{CB}$ and $18.1 \%$ of EM subjects.

\section{Circadian rhythm of symptoms in the clinical COPD phenotypes}

A higher proportion of patients suffered from respiratory symptoms in the early-morning and day-time (79.5 and 
Table 2 COPD medical history, lung function parameters and mMRC Scale score at enrollment

\begin{tabular}{|c|c|c|c|c|}
\hline & $\begin{array}{l}\text { Overall } \\
(N=606)\end{array}$ & $\begin{array}{l}C B \\
(N=351)\end{array}$ & $\begin{array}{l}\text { EM } \\
(N=215)\end{array}$ & $\begin{array}{l}\text { MCA } \\
(N=32)\end{array}$ \\
\hline COPD duration (yrs) (mean \pm SD) & $7.8 \pm 6.5$ & $7.7 \pm 6.5$ & $8.0 \pm 6.3$ & $8.7 \pm 8.9$ \\
\hline Age at COPD diagnosis (yrs) (mean \pm SD) & $63.6 \pm 9.1$ & $63.9 \pm 9.4$ & $63.5 \pm 8.1$ & $61.4 \pm 11.5$ \\
\hline $\mathrm{N}$ of COPD exacerbations/year ( 5 years before baseline) median (IQR) & $2.0(1.0-3.0)$ & $2.0(1.0-4.0)$ & $1.0(0.0-2.0)$ & $3.0(1.0-5.0)$ \\
\hline \multicolumn{5}{|l|}{ COPD assessment (GOLD guidelines) ( $N, \%)$} \\
\hline group A & $155(25.6)$ & $76(21.7)$ & $66(30.7)$ & $12(37.5)$ \\
\hline group B & $187(30.9)$ & $133(37.9)$ & $43(20.0)$ & $7(21.9)$ \\
\hline group C & $126(20.8)$ & $59(16.8)$ & $57(26.5)$ & $8(25.0)$ \\
\hline group D & $138(22.8)$ & $83(23.6)$ & $49(22.8)$ & $5(15.6)$ \\
\hline \multirow{2}{*}{$\begin{array}{l}\text { FEV1 (L) } \\
\text { Median (IQR) }\end{array}$} & $n=535$ & $n=298$ & $n=200$ & $n=29$ \\
\hline & $1.5(1.2-2.0)$ & $1.6(1.2-2.0)$ & $1.5(1.1-2.0)$ & $1.5(1.2-1.9)$ \\
\hline \multirow{2}{*}{$\begin{array}{l}\text { FEV1 of the predicted (\%) } \\
\text { Median (IQR) }\end{array}$} & $n=537$ & $n=300$ & $n=200$ & $n=29$ \\
\hline & $63.9(50.0-80.0)$ & $66.9(51.0-81.8)$ & $61.9(48.1-78.0)$ & $58.4(48.3-77.2)$ \\
\hline \multirow{2}{*}{$\begin{array}{l}\text { FVC (L) } \\
\text { Median (IQR) }\end{array}$} & $n=536$ & $n=299$ & $n=200$ & $n=29$ \\
\hline & $2.7(2.2-3.4)$ & $2.6(2.2-3.3)$ & $2.9(2.2-3.5)$ & $2.5(2.1-3.1)$ \\
\hline \multirow{2}{*}{$\begin{array}{l}\text { FEV1/FVC (\%) } \\
\text { Median (IQR) }\end{array}$} & $n=537$ & $n=300$ & $n=200$ & $n=29$ \\
\hline & $59.7(49.0-69.0)$ & $62.0(52.0-70.0)$ & $56.0(45.0-66.6)$ & $62.3(53.0-68.1)$ \\
\hline \multirow{2}{*}{$\begin{array}{l}\text { RV (L) } \\
\text { Median (IQR) }\end{array}$} & $n=291$ & $n=130$ & $n=138$ & $n=21$ \\
\hline & $3.2(2.6-4.2)$ & $2.9(2.3-3.7)$ & $3.5(2.9-4.8)$ & $3.4(2.8-4.9)$ \\
\hline \multirow{2}{*}{$\begin{array}{l}\mathrm{IC}(\mathrm{L}) \\
\text { Median (IQR) }\end{array}$} & $n=306$ & $n=143$ & $n=138$ & $n=24$ \\
\hline & $2.6(2.1-3.4)$ & $2.6(2.1-3.3)$ & $2.7(2.1-3.5)$ & $2.4(2.2-3.3)$ \\
\hline \multirow{2}{*}{$\begin{array}{l}\text { TLC (L) } \\
\text { Median (IQR) }\end{array}$} & $n=286$ & $n=128$ & $n=135$ & $n=21$ \\
\hline & $6.4(5.4-7.3)$ & $6.0(4.9-6.9)$ & $6.8(5.8-7.6)$ & $6.5(5.7-7.3)$ \\
\hline \multirow{2}{*}{$\begin{array}{l}\text { RV/TLC } \\
\text { Median (IQR) }\end{array}$} & $n=289$ & $n=128$ & $n=138$ & $n=21$ \\
\hline & $0.5(0.4-0.6)$ & $0.5(0.4-0.6)$ & $0.6(0.5-0.6)$ & $0.6(0.5-0.6)$ \\
\hline \multirow{2}{*}{$\begin{array}{l}\text { DLCO of the predicted (\%) } \\
\text { Median (IQR) }\end{array}$} & $n=205$ & $n=98$ & $n=92$ & $n=15$ \\
\hline & $68.0(51.0-83.0)$ & $69.5(59.0-87.0)$ & $63.0(46.8-76.5)$ & 76.7 (48.0-81.5) \\
\hline mMRC Scale score & $n=577$ & $n=334$ & $n=205$ & $n=30$ \\
\hline Median (IQR) & $1.0(1.0-2.0)$ & $1.0(1.0-2.0)$ & $1.0(1.0-2.0)$ & $1.0(1.0-2.0)$ \\
\hline$\geq 2(\mathrm{~N}, \%)$ & $262(45.4)$ & $150(44.9)$ & $97(47.3)$ & $11(36.7)$ \\
\hline
\end{tabular}

Data about $\mathrm{EM}+\mathrm{CB}$ not shown

$C B$ Chronic Bronchitis. DLCO diffusing capacity of the lung for carbon monoxide. EM Emphysema

FEV1 forced expiratory volume in the first second. FVC forced vital capacity. IC Inspiratory capacity. IQR interquartile range. MCA Mixed-COPD asthma. mMRC modified Medical Research Council. RV Residual Volume. SD standard deviation. TLC Total lung capacity

$79.2 \%$ in $\mathrm{CB}$ and 75.8 and $77.7 \%$ in EM groups reported early-morning and day-time symptoms, respectively) than during night-time..

Interestingly, the proportion of subjects suffering from night-time symptoms was higher in the $\mathrm{CB}$ group $(53.6 \%)$ than in the EM (39.5\%) or MCA (34.4\%) groups (Chisquare test $p$-value presence/absence of night-time symptoms vs clinical phenotype $=0.0016-$ see Fig. 2). In the subsample of patients reporting night-time symptoms, the frequency of current smokers was not significantly higher in $\mathrm{CB}(n=53,28.2 \%)$ than in EM $(n=22,25.9 \%)$ patients (Chi-square test smoke vs clinical phenotype p-value > $0.05)$. In addition, the prevalence of current smokers was unrelated to nocturnal symptoms in either CB $(n=53$, $28.2 \%$ and $n=48,29.4 \%$, symptomatic vs asymptomatic patients), EM ( $n=22,25.9 \%$ and $n=27,20.8 \%)$, or CB/EM ( $n=75,27.5 \%$ and $n=75,25.6 \%$ ).

As shown in Fig. 3a, b and c, the CB and EM phenotypes did not differ in terms of severity of respiratory symptoms for any portion of the 24-h day. The higher proportion of MCA patients with severe and moderate symptoms in each portion of the day may depend on the small sample size.

Association between circadian variability of symptoms in each clinical phenotype and severity of disease, HR-QoL, quality of sleep, level of physical activity and depression/ anxiety

In each clinical phenotype, the frequency of symptoms increased significantly with the severity of COPD (in $\mathrm{CB}$ GOLD A-D vs. presence/absence of symptoms $p$-values < 
Table 3 Quality of life, quality of sleep, level of physical activity and anxiety/depression at enrollment

\begin{tabular}{lllll}
\hline & Overall & CB & EM & MCA \\
\hline N & 582 & 339 & 204 & 32 \\
SGRQ symptoms score & $42.5 \pm 22.2$ & $43.3 \pm 22.7$ & $40.7 \pm 21.1$ & $44.4 \pm 25.3$ \\
activity score & $49.8 \pm 21.3$ & $50.4 \pm 21.4$ & $49.1 \pm 21.2$ & $48.5 \pm 22.1$ \\
impacts score & $23.5 \pm 18.7$ & $24.0 \pm 18.7$ & $22.7 \pm 18.8$ & $22.5 \pm 18.2$ \\
$\quad$ total score & $34.5 \pm 18.1$ & $35.1 \pm 18.2$ & $33.5 \pm 18.1$ & $33.9 \pm 18.5$ \\
$N$ & 597 & 344 & 213 & 32 \\
CASIS total score & $17.4 \pm 16.2$ & $19.3 \pm 16.6$ & $14.5 \pm 14.9$ & $14.3 \pm 17.1$ \\
$N$ & 566 & 332 & 196 & 30 \\
HADS Total score & $9.5 \pm 6.8$ & $9.9 \pm 6.9$ & $8.9 \pm 6.4$ & $8.8 \pm 7.1$ \\
Anxiety score & $4.9 \pm 3.7$ & $5.1 \pm 3.9$ & $4.4 \pm 3.3$ & $4.8 \pm 3.9$ \\
Depression score & $4.7 \pm 3.7$ & $4.8 \pm 3.6$ & $4.5 \pm 3.8$ & $4.0 \pm 3.6$ \\
$N$ & 199 & 113 & 72 & 11 \\
IPAQ Level of physical activity (N, \%) & & & $8(72.7)$ \\
Low & $57(28.6)$ & $40(35.4)$ & $13(18.1)$ & $3(27.3)$ \\
Moderate & $139(69.8)$ & $72(63.7)$ & $57(79.2)$ & $0(0.0)$ \\
High & $3(1.5)$ & $1(0.9)$ & $2(2.8)$ &
\end{tabular}

Data about $\mathrm{EM}+\mathrm{CB}$ not shown

Mean \pm SD (standard deviation) were shown

CASIS COPD and Asthma Sleep Impact Scale. CB Chronic Bronchitis. EM

Emphysema. HADS Hospital Anxiety and Depression Scale. IPAQ International

Physical Activity Questionnaire. MCA Mixed-COPD asthma. SGRQ St. George's

Respiratory Questionnaire
0.0005 - see Table 4). In EM, the proportions of patients of groups $\mathrm{A}$ to $\mathrm{D}$ with early-morning, day-time and nighttime symptoms were similar to those observed in $\mathrm{CB}$, although the association between GOLD classification and symptoms was not statistically significant.

As Table 4 shows, independently of clinical phenotype, the presence of symptoms during the 24-h day was associated with lower QoL (T-test p-values SGRQ scores for patients with vs. without symptoms $<0.0005$ ) and worse quality of sleep (T-test p-values CASIS score patients with vs without symptoms $<0.0005$ ).

In both the $\mathrm{CB}$ and $\mathrm{EM}$ phenotypes, mood disturbances were significantly worse in patients with day-time and nighttime symptoms: higher HADS scores were observed, in fact, in patients with vs. without symptoms (T-test p-values HADS scores patients with vs. without symptoms $<0.0005$ ). Lastly, the level of physical activity did not differ significantly between $\mathrm{CB}$ or EM patients with early-morning, day-time or night-time symptoms and those without them (see Table 4).

\section{Discussion}

The observations reported here indicate that a very high proportion of individuals suffering from COPD and under chronic inhaled medication nevertheless still show symptoms during some parts of the day. In particular, almost $80 \%$ of COPD subjects experienced symptoms during daytime or early-morning, and half had nocturnal symptoms. The novelty of this study is the relationship between circadian rhythm of symptoms and the pre-defined clinical phenotypes. Night-time symptoms, alone or in combination

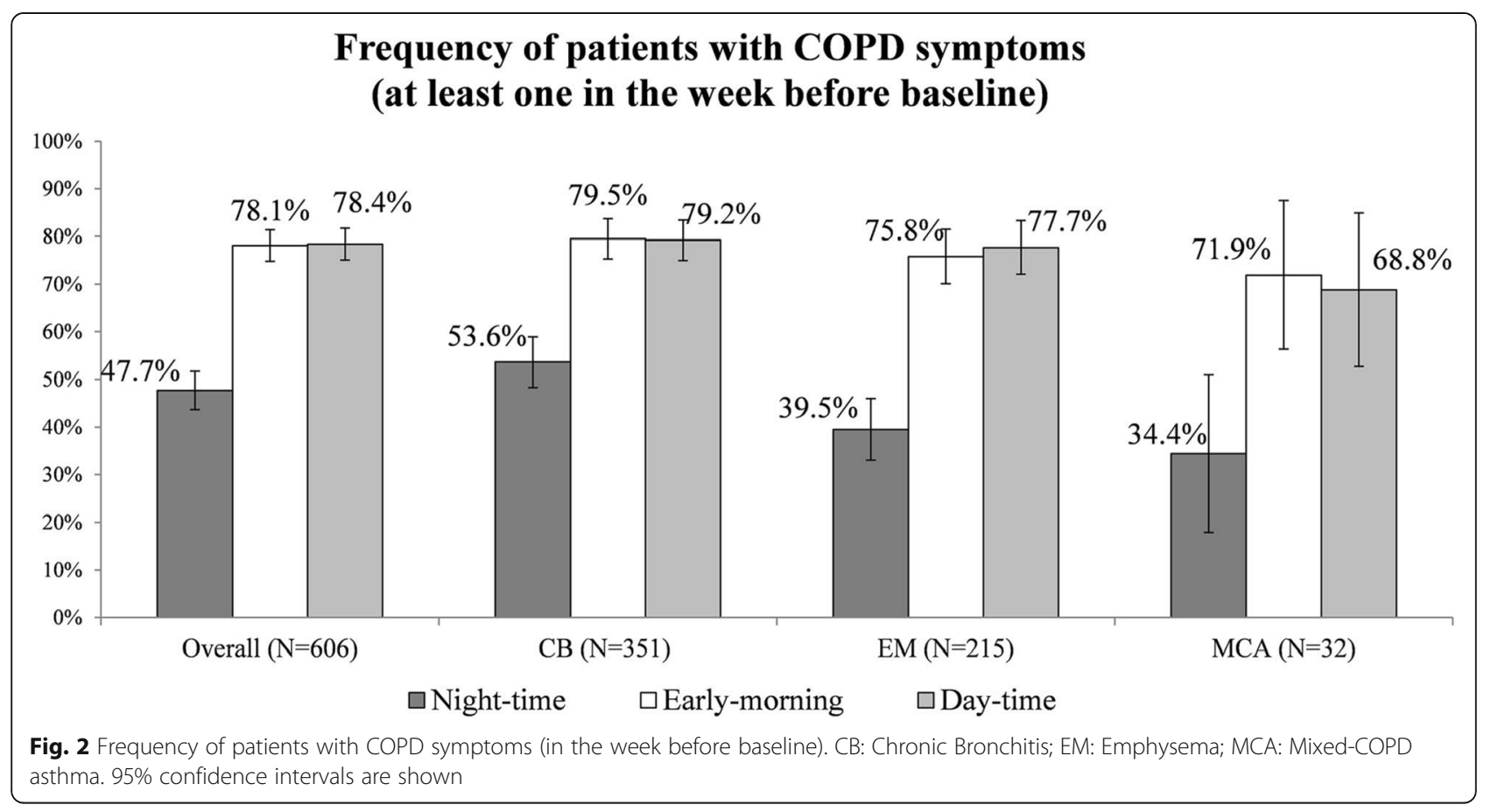




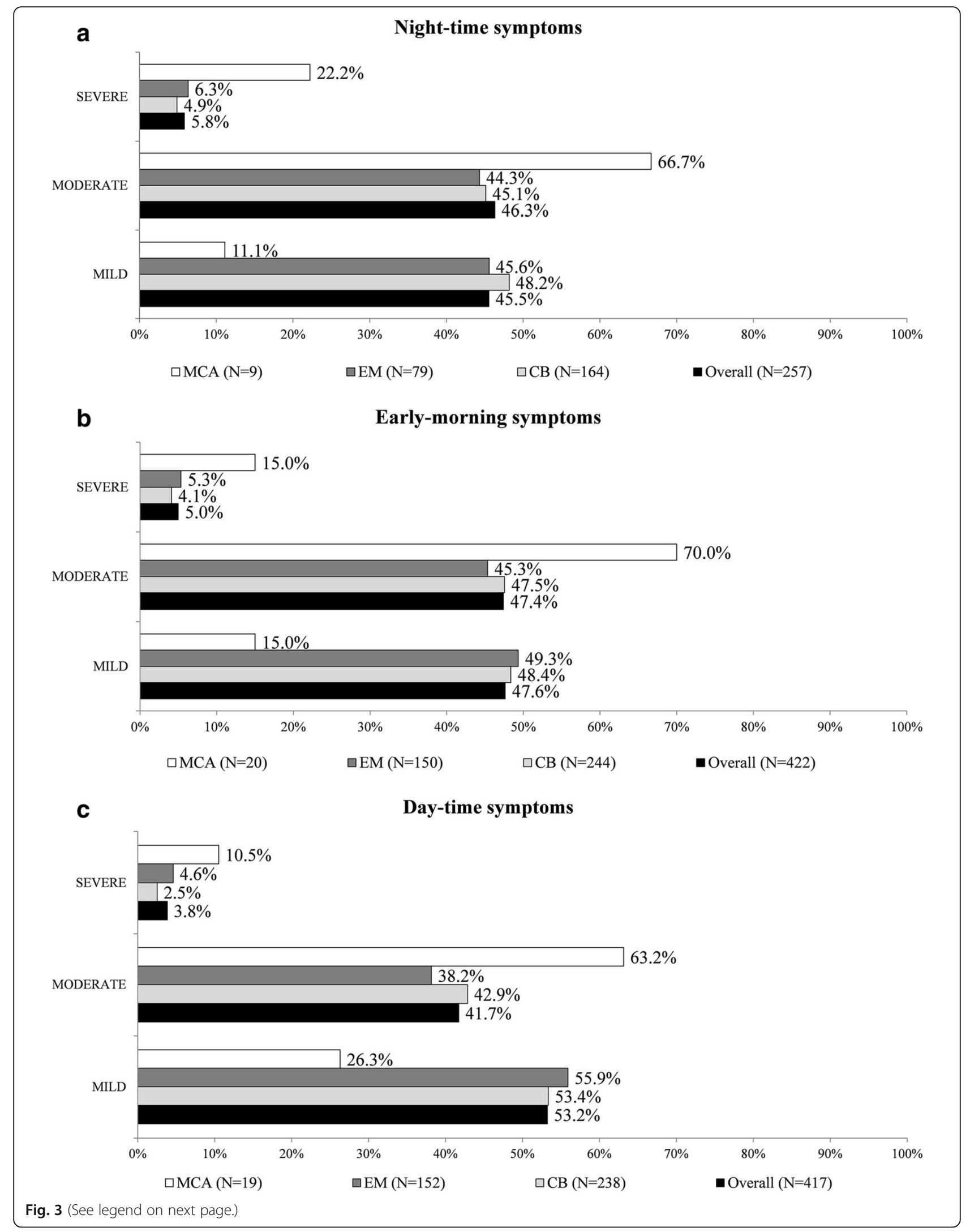


(See figure on previous page.)

Fig. 3 a Frequency of patients according to severity of night-time COPD symptoms (in the week before baseline). CB: Chronic Bronchitis; EM: Emphysema; MCA: Mixed-COPD asthma. Percentages computed out of patients with symptoms and with non-missing severity. $\mathbf{b}$ Frequency of patients according to severity of early-morning COPD symptoms (in the week before baseline). CB: Chronic Bronchitis; EM: Emphysema; MCA: Mixed-COPD asthma. Percentages computed out of patients with symptoms and with non-missing severity. c Frequency of patients according to severity of day-time COPD symptoms (in the week before baseline). CB: Chronic Bronchitis; EM: Emphysema; MCA: Mixed-COPD asthma.

Percentages computed out of patients with symptoms and with non-missing severity

with symptoms during other parts of the day, appear to characterize the CB phenotype specifically.

A previous multicenter observational investigation (ASSESS study) was conducted in European clinical practice centers to determine the prevalence and severity of respiratory symptoms during different parts of the 24-h day and other patient-reported outcomes (PROs) [12]. That study found that more than half of COPD patients had symptoms during the 24-h day, which were associated with worse PROs; interestingly, two thirds of these patients experienced night-time symptoms. The present study confirms and extends these observations: in a similar cohort of COPD subjects, nocturnal symptoms were confirmed to be very common and more frequent in the $\mathrm{CB}$ than in the EM phenotype. This finding advances our knowledge on the distinctive clinical appearance of COPD patients. Whether this is of clinical importance has yet to be demonstrated, and future confirmatory studies are required. In both CB and EM groups, night-time symptoms were associated with worse quality of life and quality of sleep and higher levels of anxiety/depression.

From a clinical standpoint, there is an urgent need to move away from the simplistic definition of COPD embracing the entire spectrum of individuals with chronic, nonreversible airway obstruction and to develop instead a classification of subgroups on the basis of common pathogenetic mechanisms and similar clinical manifestations. The commonly accepted concept of COPD is well described by the Venn diagram, which covers different clinical phenotypes and their overlap conditions [25], in the effort to classify COPD patients into distinct clinical manifestations, each of which requires specific treatment. In the present study, researchers were asked for a clinical diagnosis of the phenotype of consecutively enrolled COPD individuals based on their judgment (according to medical history and clinical characteristics). Chest imaging and lung function, when available, helped to determine or confirm the clinical decision. In this respect, the GOLD document [11] focuses mainly on symptoms and future risk in order to determine the proper treatment, with no distinction into clinical phenotypes. This missing information is likely have been a factor in the failure of large interventional clinical trials. There is no doubt that COPD patients may respond selectively to different treatments, depending on their functional and clinical manifestations, and the recent literature offers evidence in support of this concept [26-29].
The identification of clinical phenotypes, therefore, may entail prognostic consequences at the individual patient level. Since current treatment is not sufficient to control nocturnal symptoms, specific actions are strongly advocated, either a more aggressive pharmacological approach or tests of the efficacy of non-pharmacological interventions, such as pulmonary rehabilitation or non-invasive ventilation; the latter have never been investigated and warrant specially designed ad hoc studies.

The reasons for the greater prevalence of nighttime symptoms in CB individuals are unclear. Bronchial hypersecretion and the consequent accumulation of mucus during the night probably explains, at least in part, the more frequent occurrence of nocturnal symptoms. Also, the occurrence of expiratory flow limitation (EFL) at night could contribute to the respiratory symptoms. Indeed, increased bronchial vagal hypertone, typically occurring at night, and chronic inflammation and mucus, together with changes in lung volume owing to the supine position, can favor EFL, which in turn causes air trapping and pulmonary hyperinflation. In addition, cough - which is the cardinal symptom of $\mathrm{CB}$ - is a common cause of nocturnal awakening. On the other hand, dyspnea is typically effort-related in mild to moderate EM and is accordingly less severe, when the patient is at rest. Finally, one cannot rule out report bias on the part of EM patients. Indeed, night-time respiratory distress, by increasing the abdominal pressure, might induce nicturia, and this (rather than dyspnea) might, in turn, be perceived as the cause of night-time awakening, along the lines of what has been observed in elderly OSAS patients [30].

The lack of differences between the clinical phenotypes examined with specific regard to quality of life, mood changes and physical performance is somewhat surprising, and it implies clinical consequences. However, the similarities in terms of lung function impairment and dyspnea perception may have played at least some role in explaining the observed findings. It cannot be excluded that missing data for each variable explored affected the outcomes. Our present findings should improve awareness of night-time symptoms in COPD individuals. Thus, in clinical practice the occurrence of symptoms such as wheezing and coughing during the night should be subjected to routine investigation. The automated systems of long-term monitoring of respiratory symptoms now available can record respiratory symptoms during the nocturnal hours that would otherwise go unnoticed [31]. 
Table 4 Symptoms and severity of disease, HR-QoL, quality of sleep, level of physical activity and depression/anxiety

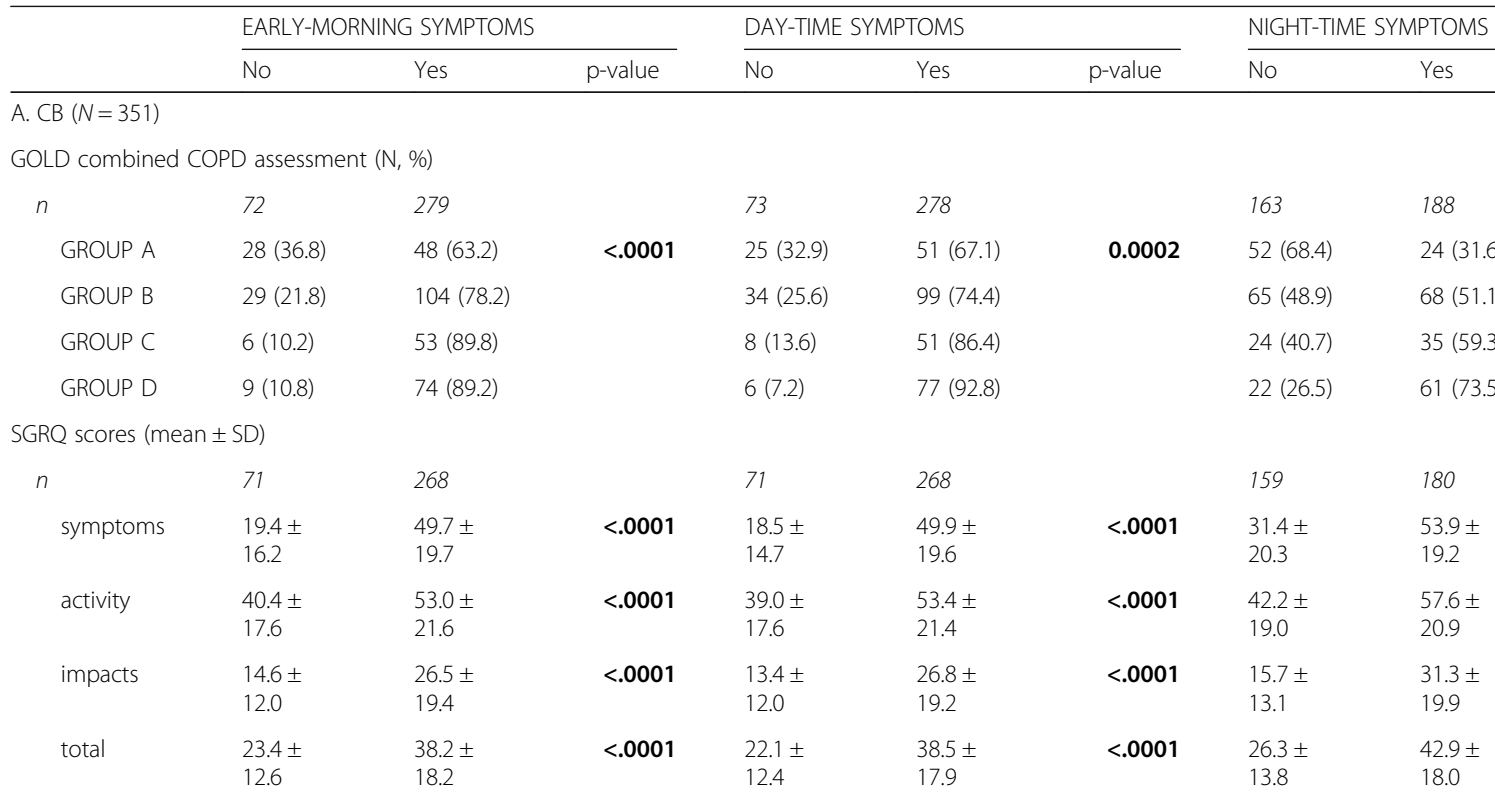
p-value

CASIS scores (mean \pm SD)

$\begin{array}{lll}n & 70 & 274 \\ \text { total } & 10.7 \pm & 21.5 \pm \\ & 12.3 & 16.8\end{array}$

274
$21.5 \pm$
16.8

$\begin{array}{lll} & 70 & 274 \\ <.0001 & 9.1 \pm 11.1 & 21.9 \pm \\ & & 16.7\end{array}$

$<0.0001$

161

$9.3 \pm 9.7$

183

HADS scores (mean \pm SD)

total

69

$8.3 \pm 6.2$

\section{3}

n

70

$10.4 \pm 7.0$

0.027

69

anxiety

$4.4 \pm 3.5$

266

n

69

$5.3 \pm 4.0$

depression

$3.8 \pm 3.0$

$5.1 \pm 3.7$

$>0.05$

$7.1 \pm 5.9$

263

70

$10.7 \pm 7.0$

$<0.0001$

266

$3.8 \pm 3.4$

$5.5 \pm 4.0$

0.0018

$69 \quad 265$

0.009

$3.3 \pm 3.0$

$5.2 \pm 3.6$

$<0.0001$

156

$8.0 \pm 6.2$

176

\section{IPAQ Level of physical activity ( $N$, \%)}

$\begin{array}{lll}n & 17 & 96 \\ \text { Low } & 4(10.0) & 36(90.0) \\ \text { Moderate } & 12(16.7) & 60(83.3) \\ \text { High } & 1(100.0) & 0(0) \\ \text { B. EM (N=215) } & & \end{array}$

$\begin{array}{lll} & 19 & 94 \\ >0.05 & 4(10.0) & 36(90.0) \\ & 14(19.4) & 58(80.6) \\ & 1(100.0) & 0(0)\end{array}$

$>0.05$

50

$19(47.5)$

63

GOLD combined COPD assessment ( $N$, \%)

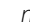

$\begin{array}{lll}\text { GROUP A } & 24(36.4) & 42(63.6) \\ \text { GROUP B } & 14(32.6) & 29(67.4) \\ \text { GROUP C } & 11(19.3) & 46(80.7) \\ \text { GROUP D } & 3(6.1) & 46(93.9)\end{array}$

SGRQ scores (mean $\pm \mathrm{SD}$ )

$\begin{array}{lll}n & 50 & 154 \\ \text { symptoms } & 20.8 \pm & 47.1 \pm \\ & 14.7 & 18.6 \\ \text { activity } & 39.7 \pm & 52.2 \pm \\ & 20.8 & 20.5 \\ \text { impacts } & 13.9 \pm & 25.5 \pm \\ & 11.5 & 19.9\end{array}$

$\begin{array}{llllll} & 48 & 167 & & 130 & 85 \\ 0.0009 & 23(34.8) & 43(65.2) & 0.0075 & 48(72.7) & 18(27.3) \\ & 10(23.3) & 33(76.7) & & 22(51.2) & 21(48.8) \\ & 11(19.3) & 46(80.7) & & 39(68.4) & 18(31.6) \\ & 4(8.2) & 45(91.8) & & 21(42.9) & 28(57.1) \\ & & & & \\ & 46 & 158 & & 122 & 82 \\ <.0001 & 23.7 \pm & 45.6 \pm & <.0001 & 33.2 \pm & 51.7 \pm \\ & 17.8 & 19.3 & & 18.9 & 19.2 \\ \mathbf{0 . 0 0 0 3} & 34.8 \pm & 53.3 \pm & <.0001 & 43.7 \pm & 57.2 \pm \\ & 17.4 & 20.4 & & 18.7 & 22.3 \\ <.0001 & 11.1 \pm 8.7 & 26.0 \pm & <.0001 & 16.1 \pm & 32.5 \pm \\ & & 19.7 & & 12.7 & 22.0\end{array}$

0.0035 
Table 4 Symptoms and severity of disease, HR-QoL, quality of sleep, level of physical activity and depression/anxiety (Continued)

\begin{tabular}{|c|c|c|c|c|c|c|c|c|c|}
\hline & \multicolumn{3}{|c|}{ EARLY-MORNING SYMPTOMS } & \multicolumn{3}{|c|}{ DAY-TIME SYMPTOMS } & \multicolumn{3}{|c|}{ NIGHT-TIME SYMPTOMS } \\
\hline & No & Yes & $p$-value & No & Yes & $p$-value & No & Yes & $p$-value \\
\hline total & $\begin{array}{l}22.7 \pm \\
13.0\end{array}$ & $\begin{array}{l}37.0 \pm \\
18.1\end{array}$ & $<.0001$ & $\begin{array}{l}20.3 \pm \\
10.6\end{array}$ & $\begin{array}{l}37.4 \pm \\
18.0\end{array}$ & $<.0001$ & $\begin{array}{l}27.1 \pm \\
13.3\end{array}$ & $\begin{array}{l}43.0 \pm \\
20.0\end{array}$ & $<.0001$ \\
\hline \multicolumn{10}{|c|}{ CASIS scores (mean \pm SD) } \\
\hline$n$ & 51 & 162 & & 47 & 166 & & 129 & 84 & \\
\hline total & $7.2 \pm 8.2$ & $\begin{array}{l}16.8 \pm \\
15.8\end{array}$ & $<.0001$ & $7.1 \pm 10.0$ & $\begin{array}{l}16.6 \pm \\
15.4\end{array}$ & $<0.0001$ & $8.0 \pm 8.7$ & $\begin{array}{l}24.6 \pm \\
16.8\end{array}$ & $<.0001$ \\
\hline \multicolumn{10}{|c|}{ HADS scores (mean \pm SD) } \\
\hline$n$ & 45 & 151 & & 42 & 154 & & 121 & 75 & \\
\hline total & $6.5 \pm 5.5$ & $9.6 \pm 6.5$ & 0.0039 & $5.1 \pm 5.1$ & $9.9 \pm 6.3$ & $<0.0001$ & $7.2 \pm 5.6$ & $11.7 \pm 6.6$ & $<0.0001$ \\
\hline$n$ & 46 & 153 & & 44 & 155 & & 123 & 76 & \\
\hline anxiety & $3.4 \pm 3.0$ & $4.8 \pm 3.3$ & 0.0079 & $2.7 \pm 2.4$ & $4.9 \pm 3.3$ & $<0.0001$ & $3.8 \pm 3.0$ & $5.5 \pm 3.5$ & 0.0002 \\
\hline$n$ & 48 & 152 & & 43 & 157 & & 123 & 77 & \\
\hline depression & $3.3 \pm 3.3$ & $4.9 \pm 3.9$ & 0.0107 & $2.6 \pm 3.2$ & $5.0 \pm 3.8$ & 0.0002 & $3.4 \pm 3.3$ & $6.2 \pm 3.9$ & $<0.0001$ \\
\hline \multicolumn{10}{|c|}{ IPAQ Level of physical activity $(\mathrm{N}, \%)$} \\
\hline$n$ & 17 & 55 & & 15 & 57 & & 54 & 18 & \\
\hline Low & $2(15.4)$ & $11(84.6)$ & $>0.05$ & $1(7.7)$ & $12(92.3)$ & 0.0265 & $8(61.5)$ & $5(38.5)$ & $>0.05$ \\
\hline Moderate & $14(24.6)$ & $43(75.4)$ & & $12(21.1)$ & $45(78.9)$ & & $44(77.2)$ & $13(22.8)$ & \\
\hline High & $1(50.0)$ & $1(50.0)$ & & $2(100.0)$ & $0(0)$ & & $2(100.0)$ & $0(0)$ & \\
\hline
\end{tabular}

The percentages of the GOLD combined COPD assessment are computed by row, i.e. over the total number of patients in Groups A, B, C, D respectively. Similarly, the percentages of IPAQ Level of physical activity are computed by row, i.e. over the total number of patients in the low, moderate, severe classes respectively

For SGRQ, CASIS and HADS scores T-test p-values (pts with symptoms vs. pts. without symptoms) are shown. Chi-square test p-values of GOLD combined COPD assessment vs. presence/absence of (early-morning, day-time, night-time) symptoms are shown. Fisher exact test p-values of IPAQ Level of physical activity vs. presence/absence of (early-morning, day-time, night-time) symptoms are shown. P-values $<0.0005$ (alpha adjusted for multiple comparisons) are in bold

CASIS COPD and Asthma Sleep Impact Scale. CB Chronic Bronchitis. EM Emphysema. HADS Hospital Anxiety and Depression Scale. IPAQ International Physical Activity Questionnaire. SGRQ St. George's Respiratory Questionnaire

Interestingly, the present study found no significant difference in level of physical activity, in either the $\mathrm{CB}$ or the EM group, between subjects with and without early-morning, day-time or night-time symptoms. This conflicts with previous studies according to which morning symptoms are responsible for limitations of physical activity and a consequent sedentary lifestyle [32, 33]. Differences between the tools used to assess morning symptoms and those used to assess the level of physical activity, as well as the items derived by the latter to perform the analysis, may help to explain the discordance between this study and those others.

The main limitation of the present study is that the STORICO study was not specifically designed to investigate differences between clinical phenotypes, so no hypotheses on the proper sizes of the groups were made a priori. As a consequence, only the CB and EM phenotypes had a large enough sample and no conclusions could be drawn with regard to MCA. Another limitation is the lack of available spirometries in a minority of the subjects enrolled. The careful evaluation of the medical history and previous functional assessment of these subjects enhanced the probability of diagnosis of COPD.
Furthermore, since lung function assessment was not included among the primary outcomes of the protocol, the main findings of the study were not affected by it. Recall bias could also have affected data collection: this is why the Night-time, Morning and Day-time Symptoms of COPD questionnaire, with its short recall period of only 1 week, was chosen to evaluate the primary objectives. Other information was usually available in medical charts or could be drawn from routine questionnaires filled out during visits.

\section{Conclusions}

In conclusion, the findings of this study indicate that the circadian rhythm of symptoms can supplement the classical phenotyping of COPD patients by revealing the prevalent phenotype-specific patterns of symptoms. Pending a confirmatory study, these findings seem robust enough to recommend systematic assessment of nocturnal symptoms and their correlates, mainly anxiety and depression, in the clinical assessment of COPD patients. This would improve our knowledge of patients' health status and, hopefully, would help to tailor COPD therapy to the individual patient. 


\section{Abbreviations}

ACO: Asthma-COPD overlap; ATS: American Thoracic Society; BMI: Body mass index; CASIS: COPD and Asthma Sleep Impact Scale; CB: Chronic bronchitis; COPD: Chronic Obstructive Pulmonary Disease; DLCO: Diffusion capacity for carbon monoxide; EFL: Expiratory flow limitation; eGFR: estimated glomerular filtration rate; EM: Emphysema; ERS: European Respiratory Society;

$F_{E V}$ : Forced expiratory volume in the first second; FVC: Forced vital capacity; GERD: Gastroesophageal Reflux Disease; GOLD: Global Initiative for Chronic Obstructive Lung Disease; HADS: Hospital Anxiety and Depression Scale; HRQoL: Health-related quality of life; IC: Inspiratory capacity; ICS: Inhaled corticosteroids; IPAQ: International Physical Activity Questionnaire; IQR: Interquartile range; LABA: Long-acting beta-agonist; LAMA: Long-acting muscarinic antagonists; MCA: Mixed COPD-asthma; mMRC: Modified Medical Research Council; NK: Unknown; PROs: Patient reported outcomes; RV: Residual Volume; SD: Standard deviation; SGRQ: St. George's Respiratory Questionnaire; TLC: Total Lung Capacity

\section{Acknowledgments}

The members of the Steering Committee (Scichilone N., Antonelli Incalzi R., Blasi F., Canonica G.W.) designed the study protocol and are responsible for the conduction of the study and the interpretation of the results; they and the other authors (Shino P., Cuttitta G., Zullo A., Ori A.) fulfil the criteria for authorship as recommended by the International Committee of Medical Journal Editors (ICMJE) and were fully responsible for all aspects of manuscript development. We are grateful to Sara Rizzoli for her help in drafting the manuscript.

STORICO study group - Participating Centers.

Pietro Schino (Acquaviva delle Fonti); Giuseppina Cuttitta (Palermo); Maria Pia Foschino (Foggia); Renato Prediletto (Pisa); Carmelindo Mario Enrico Tranfa (Naples); Maria Cristina Zappa (Rome); Pasquale Patriciello (Pollena Trocchia); Luciana Labate (Bari); Salvatore Mariotta (Rome); Stefano Nava (Bologna); Alessandro Vatrella (Salerno); Michele Mastroberardino (Avellino); Riccardo Sarzani (Ancona); Antonio luliano (Milan); Lamberto Maggi (Bergamo); Anna Zedda (Casoria); Alberto Pesci (Monza); Giuseppe Sera (Turin); Antonello Nicolini (Sestri Levante); Di Donato Salvatore Walter (Mondragone); Silvia Forte (Rome); Del Donno Mario (Benevento); Federica Rivolta (Abbiategrasso); Mauro Ferliga (Chiari); Antonio Filippo Raco (Menaggio); Di Re Luigi (Teramo); Gaetano Cabibbo (Modica); Rosario Maselli (Catanzaro); Carlo Gulotta (Orbassano); Stefano Nardini (Vittorio Veneto); Enrico Eugenio Guffanti (Casatenovo); Walter Castellani (Florence); Luca Triolo (Rome); Giovanni Passalacqua (Messina); Bianca Beghè (Modena); Lo Cicero Salvatore (Milan); Enzo Faccini (Dolo); Elena Atzeni (Nuoro); Roberto Tazza (Terni); Piercarlo Giamesio (Asti).

\section{Authors' contributions}

$\mathrm{SN}, \mathrm{AIR}, \mathrm{BF}, \mathrm{CGW}$ contributed substantially to the conception and design of the work, to data analysis and interpretation, and to the drafting and substantial revision of the work. SP and CG have made contribution to acquisition of data. ZA, OA revised the manuscript. All authors read and approved the final manuscript.

\section{Funding}

Laboratori Guidotti and Malesci, Italy provided unconditional financial support to the study. No other support was provided for the design of the study and collection, analysis, and interpretation of data and in writing the manuscript.

\section{Availability of data and materials}

The data that support the findings of this study are available from authors and Laboratori Guidotti and Malesci but restrictions apply to the availability of these data, which were used under license for the current study, and so are not publicly available. Data are however available from the authors and Laboratori Guidotti upon reasonable request. Data request may be sent to the first author (nicola.scichilone@unipa.it) and to Stefania Barsanti (Laboratori Guidotti, sbarsanti@labguidotti.it).

\section{Ethics approval and consent to participate}

The study was approved by the Ethic Committee of the coordinating center (Fondazione Toscana G. Monasterio Pisa, Italy) and was conducted in accordance with the Declaration of Helsinki and the Good Clinical Practices guidelines for observational studies, complying with all requirements of local regulations. Patients provided written, informed consent before participation.

\section{Consent for publication}

Not applicable.

\section{Competing interests}

B.F. reports grants and personal fees from ASTRAZENECA, grants and personal fees from BAYER, personal fees from CHIESI, personal fees from GSK, personal fees from GUIDOTTI, grants and personal fees from GRIFOLS, grants from INSMED, personal fees from MENARINI, personal fees from NOVARTIS, grants and personal fees from PFIZER, personal fees from TEVA, personal fees from ZAMBON, outside the scope of the work submitted.

Z.A. and O.A. are employees of Medineos Observational Research.

The other authors declare that they have no competing interests.

\section{Author details}

'DIBIMIS, University of Palermo, Piazza delle Cliniche, 2, 90127 Palermo, Italy. ${ }^{2}$ University Biomedical Campus of Rome, via Alvaro del Portillo, 21, 00128 Rome, Italy. Internal Medicine Department, Respiratory Unit and Cystic Fibrosis Adult Center Fondazione IRCCS Cà Granda Ospedale Maggiore Policlinico and Department of Pathophysiology and Transplantation, University of Milan, via Francesco Sforza, 35, 20122 Milan, Italy. ${ }^{4}$ Miulli Hospital, Acquaviva delle FontiStrada Prov. 127 Acquaviva - Santeramo Km. 4, 10070021 Bari, Italy. ${ }^{5}$ National Research Council, via Ugo La Malfa, 153, 90146 Palermo, Italy. ${ }^{6}$ Medineos Observational Research, Viale Virgilio 54/U, 41123 Modena, Italy. ${ }^{7}$ Personalized Medicine Asthma and Allergy Clinic Humanitas University Humanitas research Hospital Rozzano (Milan), via Manzoni, 56, 20089 Rozzano, MI, Italy.

Received: 13 March 2019 Accepted: 2 September 2019

Published online: 09 September 2019

\section{References}

1. Global Strategy for the Diagnosis, Management and Prevention of COPD, Global Initiative for Chronic Obstructive Lung Disease (GOLD). 2017. Available from: http://goldcopd.org. Accessed 15 Jan 2019.

2. Burrows B, Fletcher CM. Heard BE, Jones NL, Wootliff JS the emphysematous and bronchial types of chronic airways obstruction. A clinicopathological study of patients in London and Chicago. Lancet. 1966; 287(7442). https://doi.org/10.1016/S0140-6736(66)90181-4.

3. Miravitlles M, Soler-Cataluña JJ, Calle M, Molina J, Almagro P, Quintano JA, Riesco JA, et al. Spanish COPD guidelines (GesEPOC). Update 2014. Arch Bronconeumol. 2014;50(Suppl 1):1-16. https://doi.org/10.1016/S03002896(14)70070-5.

4. Orie NGM, Sluiter HJ, De Vries K, Tammeling GJ, Witkop J. The host factor in bronchitis. In: Orie NGM, Sluiter HJ, editors. Bronchitis. Assen: Royal Van Gorcum; 1961. p. 43-59.

5. Barnes PJ. Against the Dutch hypothesis: asthma and chronic obstructive pulmonary disease are distinct diseases. Am J Respir Crit Care Med. 2006; 174(3):240-3 discussion 243-4.

6. Bonten TN, Kasteleyn MJ, de Mutsert R, Hiemstra PS, Rosendaal FR. Chavannes $\mathrm{NH}$ et al, defining asthma-COPD overlap syndrome: a population-based study. Eur Respir J. 2017;49:160.

7. Canonica GW, Blasi F, Scichilone N, Simoni L, Zullo A, Giovannetti C, et al. On behalf of STORICO study group characterization of circadian COPD symptoms by phenotype: methodology of the STORICO observational study. Eur J of Intern Med. 2017;43:62-8.

8. Global Initiative for Chronic Obstructive Lung Disease (GOLD). Global Strategy for the Diagnosis, Management and Prevention of COPD: 2014. Available from: http://goldcopd.org.

9. Miravitlles M, Soler-Cataluña JJ, Calle M, Molina J, Almagro P, Quintano JA, et al. Spanish COPD guidelines (GesEPOC): pharmacological treatment of stable COPD. Arch Bronconeumol. 2012;48(7):247-57. https://doi.org/10. 1016/j.arbres.2012.04.001

10. Lange P, Halpin DM, O'Donnell DE, MacNee W. Diagnosis, assessment, and phenotyping of COPD: beyond FEV1. Int J Chron Obstruct Pulmon Dis. 2016;11:3-12 (Spec Iss).

11. Global Initiative for Chronic Obstructive Lung Disease (GOLD). Global Strategy for the Diagnosis, Management and Prevention of COPD: 2016 Available from: http://goldcopd.org. 
12. Miravitlles M, Worth H, Soler Catalauña JJ, Price D, De Benedetto F, Roche N, Godtfredsen NS, et al. Observational study to characterize 24-hour COPD symptoms and their relationship with patient-reported outcomes; results from the ASSESS study. Respir Res. 2014;15:122. https://doi.org/10.1186/s12931-014-0122-1.

13. Charlson M, Pompei P, Ales KL, MacKenzie CR. A new method of classifying prognostic comorbidity in longitudinal studies: development and validation. J Chronic Dis. 1987;40(5):373-83.

14. Jones $P$, Lareau $S$, Mahler DA. Measuring the effects of COPD on the patient. Respir Med. 2005;99(Suppl B):S11-8.

15. Jones PW, Quirk FH, Baveystock CM. The St George's respiratory questionnaire. Respir Med. 1991;85(Suppl. B):25-31.

16. Jones PW, Quirk FH, Baveystock CM, Littlejohns P. A self-complete measure for chronic airflow limitation - the St George's respiratory questionnaire. Am Rev Respir Dis. 1992;145:1321-7.

17. Meguro M, Barley EA, Spencer S, Jones PW. Development and validation of an improved COPD-specific version of the St George's respiratory questionnaire. Chest. 2006;132:456-63.

18. Zigmond AS, Snaith RP. The hospital anxiety and depression scale. Acta Psychiatr Scand. 1983;67:361-70.

19. Herrmann C. International experiences with the hospital anxiety and depression scale - a review of validation data and clinical results. J Psychosom Res. 1997;42:17-41.

20. Barth J, Martin CR. Factor structure of the hospital anxiety and depression scale (HADS) in German coronary heart disease patients. Health Qual Life Outcomes. 2005;3:15.

21. Pokrzywinski RF, Meads DM, McKenna SP, Glendenning GA, Revicki DA. Development and psychometric assessment of the COPD and asthma sleep impact scale (CASIS). Health Qual Life Outcomes. 2009;7:98.

22. Ainsworth BE, Bassett DR Jr, Strath SJ, Swartz AM, O'Brien WL, Thompson RW, et al. Comparison of three methods for measuring the time spent in physical activity. Med Sci Sports Exerc. 2000;32:S457-64.

23. Guidelines for Data Processing and Analysis of the International Physical Activity Questionnaire (IPAQ) - Short and Long Forms November 2005.

24. National Kidney Foundation. KDOQI clinical practice guidelines for chronic kidney disease: evaluation, classification, and stratification. Am J Kidney Dis. 2002;39(2 suppl 1):S1-266.

25. Soriano JB, Alfageme I, Almagro P, Casanova C, Esteban C, Soler-Cataluña JJ, et al. Distribution and prognostic validity of the new Global Initiative for Chronic Obstructive Lung Disease grading classification. Chest. 2013;143(3):694-702.

26. Rabe KF, Wedzicha JA. Controversies in treatment of chronic obstructive pulmonary disease. Lancet. 2011;378(9795):1038-47.

27. Miravitlles M, Soler-Cataluña JJ, Calle M, Soriano JB. Treatment of COPD by clinical phenotypes: putting old evidence into clinical practice. Eur Respir J. 2013;41(6):1252-6.

28. Cheng SL, Wang HH, Lin CH. Effect of allergic phenotype on treatment response to inhaled bronchodilators with or without inhaled corticosteroids in patients with COPD. Int J Chron Obstruct Pulmon Dis. 2017;12:2231-8.

29. Pavord ID, Chanez P, Criner GJ, Kerstjens HAM, Korn S, Lugogo N, et al. Mepolizumab for eosinophilic chronic obstructive pulmonary disease. N Engl J Med. 2017:377(17):1613-162

30. Endeshaw YW, Johnson TM, Kutner MH, Ouslander JG, Bliwise DL. Sleep-disordered breathing and nocturia in older adults. J Am Geriatr Soc. 2004;52(6):957-60.

31. Krönig J, Hildebrandt O, Weissflog A, Cassel W, Gross V, Sohrabi K, Fischer P, Koehler U. Long-term recording of night-time respiratory symptoms in patients with stable COPD II-IV. COPD. 2017;14(5):498-503. https://doi.org/ 10.1080/15412555.2017.1338681.

32. van Buul AR, Kasteleyn MJ, Chavannes NH, Taube C. Physical activity in the morning and afternoon is lower in patients with chronic obstructive pulmonary disease with morning symptoms. Respir Res. 2018;19(1):49. https://doi.org/10.1186/s12931-018-0749-4.

33. van Buul AR, Kasteleyn MJ, Chavannes NH, Taube C. The association between objectively measured physical activity and morning symptoms in COPD. Int J Chron Obstruct Pulmon Dis. 2017;12:2831-40. https://doi.org/10. 2147/COPD.S143387.eCollection2017.

\section{Publisher's Note}

Springer Nature remains neutral with regard to jurisdictional claims in published maps and institutional affiliations.

Ready to submit your research? Choose BMC and benefit from:

- fast, convenient online submission

- thorough peer review by experienced researchers in your field

- rapid publication on acceptance

- support for research data, including large and complex data types

- gold Open Access which fosters wider collaboration and increased citations

- maximum visibility for your research: over $100 \mathrm{M}$ website views per year

At BMC, research is always in progress.

Learn more biomedcentral.com/submissions 